Journal of Mathematics and Informatics

Vol. 7, 2017, 27-35

ISSN: 2349-0632 (P), 2349-0640 (online)

Published 20 March 2017

www.researchmathsci.org

DOI: http://dx.doi.org/10.22457/jmi.v7a4

Journal of

Mathematics and

Informatics

\title{
Evolutionary Game Analysis of Internet Information Service Enterprise Behavior Evolved by Accompanying Diffusion
}

\author{
An-wen Lu and De-xing Kong \\ School of Economics and Management \\ Chongqing University of Posts and Telecommunications \\ Chongqing-400065, China \\ E-mail: \{law130, Kongdx130\} @163.com
}

Received 9 March 2017; accepted 18 March 2017

\begin{abstract}
Due to the accompanying diffusion of Internet information service products, the behavior of enterprises is complex and diverse, which hinders the enterprise's own behavior choice and the government's regulation over the enterprise. Using evolutionary game theory, this paper divides the game into the incumbent enterprise and the entry enterprise and studies the problem of enterprise behavior choice under the diffusion of industry products, and makes a simulation analysis with Matlab. The results show that the network externalities of incumbent enterprise, entry cost, the distribution of interests between the two sides, the compatible cost of the incumbent enterprises is the key factor affecting the evolutionary game system. By rationally guiding the distribution of benefits among enterprises, reducing the compatible cost and the entry cost, it can help guide enterprises to cooperate, and thus promote the healthy and sustainable development of the industry.
\end{abstract}

Keywords: Internet information service enterprise; accompanying diffusion; enterprise behavior; evolutionary game

AMS Mathematics Subject Classification (2010): 91A22

\section{Introduction}

With the progress of technology and cross- domain competition, the Internet information service industry business boundaries are no longer obvious, combined with the industry itself has a clear network externalities, accompanying diffusion of product has become the main method of Internet information service enterprises [1]. This diffusion of product in Internet information services has had a profound impact. The market of enterprises can be divided into the incumbent enterprise and entry enterprise, and then in the role of product diffusion they take cross- domain competition in enterprise behavior.

A behavioral theory of the firm has always been a hot issue in the research field, which lays the foundation for the decision making and strategic choice of the enterprise with limited rationality and incomplete information [2, 3, 4]. In [5], Prietula and Watson started from a behavioral theory of the firm and studied the choice of enterprise behavior 


\section{An-Wen Lu and De-Xing Kong}

strategy in duopoly market. In [6], O'Brien, Jonathan, and David studied the influence of a behavioral theory of the firm on the decision-making of enterprise R \& D strategy.

In the Internet information services, accompanying diffusion of product, enterprise behavior and network externalities are closely related. In the early stage, the research on the market entry of enterprises under the condition of network externality is mainly concerned with the choice of the entry strategy of the enterprise from the perspective of the supply side and the enterprise [7,8]. After that, the research on the combination of network externality, product diffusion and market entry mainly focuses on customers' choice of diffusion products, compatibility between enterprises and so on. In [9], Chou and Shy studied the impact of consumer preferences and the purchase of product accessories on the final consumption decision, that indirect network effects can cause real externality. In [10], Karaca-Mandic started from the indirect network externalities and believed that the completeness of complementary products and compatible products have a new technology or new product enterprise users have an important impact on the accumulation of complementary products or compatible products on the market. New technology is more easily accepted by consumers for the use is more convenient, so it is more able to get a successful market entry. For the choice of corporate behavior in the network externality environment, the Chinese scholar Chen and his team carried out a more systematic study $[11,12,13,14]$. In [11], they studied the impact of different ways of entry on enterprise profits under the network externalities. In [12], they studied the entry and compatibility issues through the construction of three-stage game model and found that the network externalities and costs is the decisive factor in enterprise entry. In [13], they introduced the transfer cost, suggesting that the transfer cost is a key influencing factor in the compatibility strategy selection in addition to the network externalities, and this effect is particularly pronounced in markets with vertical product differentiation. In [14], they regarded the network externality as the research object, that the network externalities in the market structure adjustment plays a key role, mainly in the network externalities can be used as a market barrier to the enterprise entry.

The above research has achieved rich results, but has not been able to fully explain and determine the Internet information services enterprise's behavior with the products accompanying diffusion. The main reason is, first, the study of the accompanying diffusion of products is focusing on consumer purchasing decision-making level, and attached to the accompanying diffusion of enterprise impact on the study is still rare; Second, the existence of network externality under the conditions of enterprise behavior research cannot explain the choice of enterprise behavior process and determine the final equilibrium results under the condition of irregular competition and cooperation in the industry. Therefore, based on the bounded rationality and incomplete information in the theory of enterprise behavior, this paper uses the evolutionary game to analyze the enterprise behavior and studies the evolution of enterprise behavior and the market Trend, to solve the problem of enterprise behavior selection, to provide a certain theoretical basis for reducing the industry unfair competition.

\section{Basic assumptions}

The research scope is the Internet information service market with network externality. According to the accompanying characteristics of the diffusion, the enterprises on the market are abstracted into two categories -the incumbent enterprise and the entry 
Evolutionary Game Analysis of Internet Information Service Enterprise Behavior Evolved by Accompanying Diffusion

enterprise. Entry enterprise in a certain area has achieved a certain market position, hoping to spread through the product into other areas or market to get more profits, the strategy set for (enter, do not enter), and incumbent enterprise can choose their products compatible with or not, its strategy set (compatible, not compatible).

$\pi_{1}$ The income gained by enterprises enter a certain market, and $\pi_{1}=\alpha_{1} n_{1} r$ [13]

$\alpha_{1}$ Network Externality Intensity Coefficient of entry enterprise

$n_{1}$ The number of expected users in a particular field of entry enterprise

$r$ The Convergence Coefficient of Enterprise Network Effect

$\pi_{2}$ The income gained of incumbent enterprise, and $\pi_{2}=\alpha_{2} n_{2} r$

$\alpha_{2}$ Network Externality Intensity Coefficient of incumbent enterprise

$n_{2}$ The number of expected users in a particular field of incumbent enterprise

$V$ The additional income if incumbent enterprise is compatible to the enterprise product

$\lambda$ The proportion of the additional income of incumbent enterprise

$T$ Compatibility cost

$C$ Entry cost

$F$ Competitive cost when incumbent enterprises are incompatible

\section{Model construction}

Based on the assumptions in section 2, we establish the evolution game payoff matrix of the Internet information service between incumbent enterprise and entry enterprise. Table 1.

The revenue matrix of the incumbent enterprise and the entry enterprise is shown in

Table 1: Incumbent enterprise and entry enterprise Revenue Matrix

\begin{tabular}{c|c|c}
\hline $\begin{array}{c}\text { Incumbent } \\
\text { enterprise } \\
\text { Entry enterprise }\end{array}$ & Compatible $(y)$ & Not compatible $(1-y)$ \\
\hline Enter $(x)$ & $\pi_{1}+(1-\lambda) v-C, \pi_{2}+\lambda v-T$ & $\pi_{1}-C-F, \pi_{2}-F$ \\
\hline Do not enter $(1-x)$ & $0, \pi_{2}-T$ & $0, \pi_{2}$ \\
\hline
\end{tabular}

The income of entry enterprise that enter other market is $U_{A 1}$, and that do not enter other market is $U_{A 2}$. The average income is $\bar{U}_{A}$. Thus,

$$
\begin{aligned}
& U_{A 1}=y\left[\pi_{1}+(1-\lambda) v-C\right]+(1-y)\left(\pi_{1}-C-F\right) \\
& U_{A 2}=y \cdot 0+(1-y) \cdot 0=0 \\
& \bar{U}_{A}=x U_{1}+(1-x) U_{2}=x y(1-\lambda) v+x \pi_{1}-x C-x F+x y F
\end{aligned}
$$

From (1) - (3), it can get the replicator dynamic equation of entry enterprise: 
An-Wen Lu and De-Xing Kong

$$
F(x)=\frac{d x}{d t}=x\left(U_{1}-\bar{U}\right)=x(1-x)\left[y(1-\lambda) v+\pi_{1}-C-F+y F\right]
$$

The income of the incumbent enterprise which is compatible is $U_{B 1}$, and that is not compatible is $U_{B 2}$. The average income is $\bar{U}_{B}$. Thus,

$$
\begin{aligned}
& U_{B 1}=x\left(\pi_{2}+\lambda v-T\right)+(1-x)\left(\pi_{2}-T\right) \\
& U_{B 2}=x\left(\pi_{2}-F\right)+(1-x) \pi_{2} \\
& \bar{U}_{B}=y\left(x \lambda v+\pi_{2}-T\right)+(1-y)\left(-x F+\pi_{2}\right)
\end{aligned}
$$

From (5) - (7) can be obtained the replicator dynamic equation of incumbent enterprise:

$$
G(y)=\frac{d y}{d t}=y(1-y)(x \lambda v-T+x F)
$$

Equations (4) and (8) form an evolutionary dynamical system between incumbent enterprise and entry enterprise. Let $\mathrm{F}(\mathrm{x})=0$ and $\mathrm{G}(\mathrm{y})=0$, then the evolution equilibrium of the system is $(0,0),(0,1),(1,0),(1,1)$ and $\left(\frac{T}{\lambda v+F}, \frac{C+F-\pi_{1}}{(1-\lambda) v+F}\right)$.

In order to facilitate the analysis of the stability of the system and the equilibrium point, so that $A=\frac{T}{\lambda v+F}, B=\frac{C+F-\pi_{1}}{(1-\lambda) v+F}$.

The equilibrium point obtained by replicating the dynamic equation is not necessarily the evolution stabilization strategy (ESS). It can analyze and study the local stability of the system according to the local stability of the corresponding Jacobian matrix.

$$
J=\left[\begin{array}{ll}
\frac{\partial F(x)}{\partial x} & \frac{\partial F(x)}{\partial y} \\
\frac{\partial G(y)}{\partial x} & \frac{\partial G(y)}{\partial y}
\end{array}\right]=\left[\begin{array}{ll}
a_{11} & a_{12} \\
a_{21} & a_{22}
\end{array}\right]=\left[\begin{array}{lc}
(1-2 x)\left(\pi_{1}-\pi_{2}+y s\right) & x(1-x) s \\
0 & (2 y-1) c
\end{array}\right]
$$

If the following two conditions are satisfied simultaneously, then the equilibrium point of the replicate dynamic equation is the ESS:

(1) $\operatorname{tr} J=a_{11}+a_{22}<0$ (trace conditions);

(2) $\operatorname{det} J=\left|\begin{array}{ll}a_{11} & a_{12} \\ a_{21} & a_{22}\end{array}\right|=a_{11} a_{22}-a_{12} a_{21}>0$ (Jacques ratio determinant conditions).

The five local equilibrium point values into its expression are shown in Table 2. The specific expressions of $\mathrm{M}$ and $\mathrm{N}$ are as follows:

$$
M=\frac{T}{\lambda v+F}\left(1-\frac{T}{\lambda v+F}\right)[(1-\lambda) v+F], N=\frac{C+F-\pi_{1}}{(1-\lambda) v+F}\left(1-\frac{C+F-\pi_{1}}{(1-\lambda) v+F}\right)(\lambda v+F)
$$


Evolutionary Game Analysis of Internet Information Service Enterprise Behavior Evolved by Accompanying Diffusion

Table 2: Equilibrium point numerical expression

\begin{tabular}{ccccc}
\hline $\begin{array}{c}\text { Equilibrium } \\
\text { point }\end{array}$ & $a_{11}$ & $a_{12}$ & $a_{21}$ & $a_{22}$ \\
\hline$(0,0)$ & $\pi_{1}-C-F$ & 0 & 0 & $-T$ \\
$(0,1)$ & $(1-\lambda) v+\pi_{1}-C$ & 0 & 0 & $T$ \\
$(1,0)$ & $-\left[\pi_{1}-C-F\right]$ & 0 & 0 & $\lambda v+F-T$ \\
$(1,1)$ & $-\left[(1-\lambda) v+\pi_{1}-C\right]$ & 0 & 0 & $-[\lambda v+F-T]$ \\
$(\mathrm{A}, \mathrm{B})$ & 0 & $M$ & $N$ & 0 \\
\hline
\end{tabular}

Obviously at the equilibrium point $(\mathrm{A}, \mathrm{B}), t r J=0$. It does not satisfy the trace condition in the above, so the equilibrium point $(\mathrm{A}, \mathrm{B})$ is not the evolution stabilization strategy of the system. Therefore, we need to judge the remaining four points, combined with the conditions set forth in the previous article, we analyze the above four equilibrium points, we can draw the following conclusions:

(1) If $\pi_{1}-C-F<0, T>0$, then $(0,0)$ is the evolutionary stability strategy of the system;

(2) If $\pi_{1}-C-F>0, \lambda v+F-T<0$ and $\pi_{1}-C+\lambda v-T<0$, then $(1,0)$ is the evolutionary stabilization strategy of the system;

(3) If $(1-\lambda) v+\pi_{1}-C>0$ and $\lambda v+F-T>0$, then $(1,1)$ is the evolutionary stability strategy of the system;

(4) The compatibility cost is always greater than zero, and there is no $(0,1)$ for the evolution stabilization strategy.

The stabilization strategy of the system of (1), (2) and (3) are shown in Tables 3, 4 and 5 respectively.

Table 3: Local stability of the equilibrium point of (3)

\begin{tabular}{cccc}
\hline Equilibrium point & $t r J$ & $\operatorname{det} J$ & Stability \\
\hline$\left(\begin{array}{ll}0 & 0\end{array}\right)$ & - & + & ESS \\
$\left(\begin{array}{ll}0 & 1\end{array}\right)$ & indefinite & - & Saddle point \\
$\left(\begin{array}{ll}1 & 0\end{array}\right)$ & + & + & Unstable point \\
$(1,1)$ & indefinite & - & Saddle point \\
\hline
\end{tabular}

Table 4: Local stability of the equilibrium point of (4)

\begin{tabular}{cccc}
\hline Equilibrium point & $t r J$ & $\operatorname{det} J$ & Stability \\
\hline$\left(\begin{array}{ll}0 & 0\end{array}\right)$ & indefinite & - & Saddle point \\
$\left(\begin{array}{ll}0 & 1\end{array}\right)$ & + & + & Unstable point \\
$\left(\begin{array}{ll}1 & 0\end{array}\right)$ & - & + & ESS \\
$(1,1)$ & indefinite & - & Saddle point \\
\hline
\end{tabular}




\section{An-Wen Lu and De-Xing Kong}

Table 5: Local stability of the equilibrium point of (4)

\begin{tabular}{cccc}
\hline Equilibrium point & $t r J$ & det $J$ & Stability \\
\hline$(0,0)$ & indefinite & - & Saddle point \\
$(0,1)$ & + & + & Unstable point \\
$(1,0)$ & indefinite & - & Saddle point \\
$(1,1)$ & - & + & ESS \\
\hline
\end{tabular}

\section{Model simulation analysis}

In order to explore the choice of enterprise behavior strategy, we will use MATLAB software evolution simulation of changes in specific parameters. Then the evolution of incumbent enterprise and entry enterprise in the game process stability strategy are used to analyze the simulation results.

(1) If $\pi_{1}-C-F<0, T>0$, then $(0,0)$ is the evolutionary stability strategy of the system.

When $\lambda=0.4, v=30, \pi_{1}=20, C=50, F=30, T=30$, it meets the hypothesis requirements above. The simulation results are shown in Fig. 1. According to the number of evolutionary iterations, the evolutionary stabilization strategy of incumbent enterprise and entry enterprise tends to $(0,0)$.

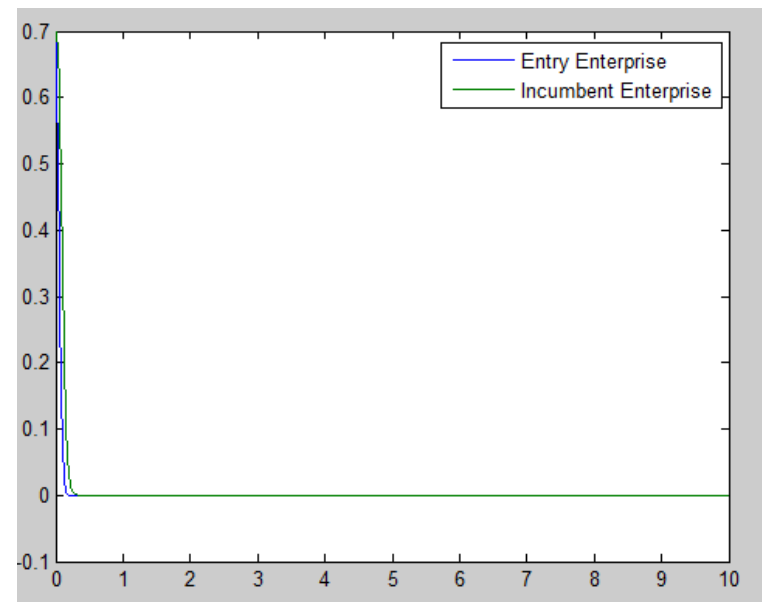

Figure 1: Stable point $(0,0)$ evolution simulation results

As shown in Figure 1, when entry enterprise's entry cost and competitive cost are more than the income gained from entering the market, entry enterprise tends not to enter the market. And with entry enterprise reduces the probability of enter the market and in the presence of compatible cost, incumbent enterprise tends to adopt incompatible strategy.

(2) If $\pi_{1}-C-F>0, \lambda v+F-T<0$ and $\pi_{1}-C+\lambda v-T<0$, then $(1,0)$ is the evolutionary stabilization strategy of the system.

When $\lambda=0.4, v=30, \pi_{1}=40, C=20, F=10, T=30$, it meets the hypothesis requirements above. The simulation results are shown in Fig. 2. As the number of 
Evolutionary Game Analysis of Internet Information Service Enterprise Behavior Evolved by Accompanying Diffusion

evolutionary iterations increases, entry enterprise gradually adopts enter the market. Incumbent enterprise gradually adopts incompatible strategy, and the evolution stabilization strategy is $(1,0)$.

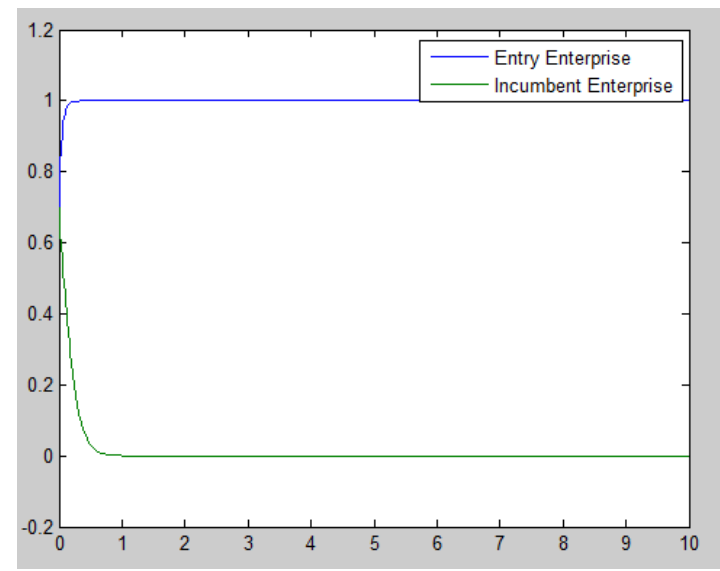

Figure 2: Stable point $(1,0)$ evolution simulation results

When entry enterprise's income is greater than the entry cost and competitive cost of conflict, entry enterprise's choice strategy is to enter the market. But incumbent enterprise's strategy is still incompatible because of sharing small benefits and compatible cost is large. This situation is easy to directly lead to conflicts of enterprises, in order to maintain their own interests incumbent enterprise is not compatible with entry enterprise's product, triggering the conflict between the two sides, which may lead to unfair competition.

(3) If $(1-\lambda) v+\pi_{1}-C>0$ and $\lambda v+F-T>0$, then $(1,1)$ is the evolutionary stability strategy of the system.

When $\lambda=0.4, v=30, \pi_{1}=40, C=20, F=20, T=20$, it meets the hypothesis requirements above. The simulation results are shown in Fig. 3.

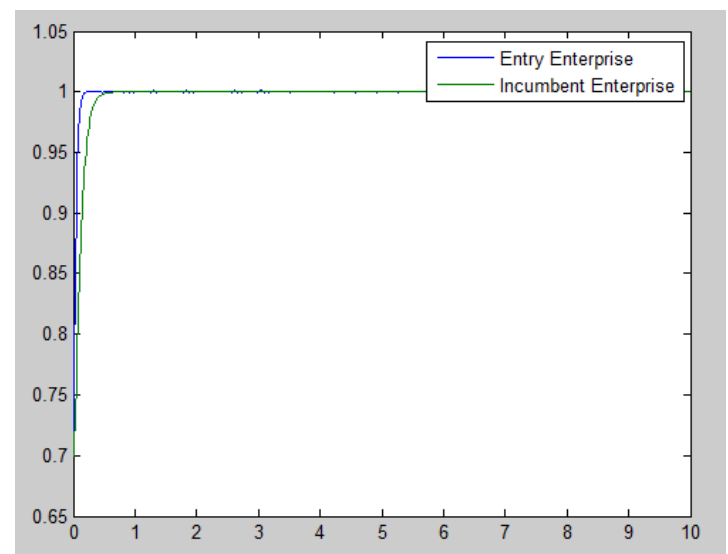

Figure 3: Stable point $(1,0)$ evolution simulation results 


\section{An-Wen Lu and De-Xing Kong}

As the number of evolutionary iterations increases, entry enterprise gradually adopts enter the market. Incumbent enterprise gradually adopts compatible strategy, and the evolution stabilization strategy is $(1,1)$.

According to this situation, due to the reduction of the compatible cost, the choice of the enterprise behavior of both sides is to entry enterprise to enter the market, incumbent enterprise chooses to be compatible. The cause of this situation is that the enterprises of both sides can get the satisfaction of their own profits. The entry enterprise's share of benefits and the proceeds after entry is greater than the enter cost, and incumbent enterprise's benefit sharing and the cost of conflict due to the compatibility of alternatives are larger than that of the compatible cost. Therefore, the evolution strategy of both enterprises' behavior is (enter, compatible).

\section{Conclusion}

Based on the knowledge of enterprise behavior theory, and in the case of bounded rationality and information asymmetry, this paper applies the evolutionary game theory to the Internet information service enterprise behavior selection which under the accompanying diffusion of product, and then establishes the enterprise choice strategy evolutionary game model. By solving the corresponding replicated dynamic equation and build simulation for analysis, we found that the network externalities, entry costs, the distribution of interests of both parties, and the compatibility costs of the incumbent enterprises are the key factors which influence the evolutionary game system. According to the above conclusions, the measures which can promote cooperation between enterprises compatible and reduce unfair competition from the government perspective are as follows.

First, guide the distribution of benefits between enterprises reasonably. The power of entry enterprises enter the market is the benefits which they can get after the entry, and the prerequisites for compatibility of the incumbent enterprises is the benefits of sharing. The government should guide the distribution of the enterprises' benefits, do a good job to protect enterprises whether it is large enterprises, or small businesses, and protect their legitimate benefits, reduce the possibility of unfair competition.

Second, reduce the compatibility cost of incumbent enterprises. The government should encourage incumbent enterprises to compatible, it can through a certain incentive measures such as compatible incentives, reduce taxes to reduce the cost, and protect the diversity of the market, and then to promote fair and reasonable competition in the industry.

Third, reduce the entry cost of the entry enterprise. Through our model, we can find reduce the entry cost can promote the enterprise enter the market. Therefore, the government should make some measures to reduce the enterprises' entry cost, such as reducing market entry barriers and corporate taxation, and encouraging enterprises to innovate. By reducing the entry costs of enterprises, thereby stimulating market vitality and promoting the development of the industry.

The conclusion of this paper also can use to government regulation. From the conclusion of the paper, we find if the enterprises have strong user sticky and large number of users, they can easily get succeed when entry other market areas through the proliferation. Therefore, these enterprises easy to achieve "winners take-all" effect when market competition. This means a monopolistic expansion of the Internet business 


\section{Evolutionary Game Analysis of Internet Information Service Enterprise Behavior Evolved by Accompanying Diffusion}

community. Moreover, it not conducive to the survival of small and medium enterprises in some areas, and hinder the industry innovation. Therefore, when the government regulates the industry, it should pay attention to the supervision of these enterprises, to prevent the formation of its market monopoly power, and then also should conduct realtime supervision and timely stop to the emergence of improper behavior, such as the user bundles and improper asking price.

\section{Acknowledgements}

This work is supported by the National Social Science Foundation of China (No. 14BGL107).

\section{REFERENCES}

1. Z.Liu, Behavioral operations management: An emerging research field, Journal of Management Sciences in China, 12 (4) (2009) 64-74.

2. H.R.Greve, Performance aspirations, and risky organizational change, Administrative Science Quarterly, 43(1) (1998) 58.

3. N.R.Sanders, B.S.Fugate and Z.G.Zacharia, Interdisciplinary research in SCM: through the lens of the behavioral theory of the firm, Journal of Business Logistics, 37(2) (2016) 107-112.

4. D.A.Levinthal, The behavioral theory of the firm: assessment and prospects, Academy of Management Annals, 6 (1) (2012) 1-40.

5. M.J.Prietula and H.S.Watson, When behavior matters: games and computation in a behavioral theory of the firm, Journal of Economic Behavior \& Organization, 66(1) (2008) 74-94.

6. J.P.O'Brien and P.David, Reciprocity and R\&D search: Applying the behavioral theory of the firm to a communitarian context, Strategic Management Journal, 35(4) (2014) 550-565.

7. M.L.Katz and C.Shapiro, Systems competition and network effects, Journal of Economic Perspective, 8(8) (1994) 93-115.

8. P.Klemperer, The competitiveness of markets with switching costs, Rand Journal of Economics, 18(1) (1987) 138-150.

9. C.F.Chou and O.Shy, Network effects without network externalities, International Journal of Industrial Organization, 8(2) (1990) 259-270.

10. P.Karaca-Mandic, Network effects in technology adoption: the case of DVD players, Department of Economics, Institute for Business and Economic Research, UC Berkeley, 2003.

11. X.Shuai and H.M.Chen, Market Entry and network externalities, Systems Engineering, (2003).

12. J.I.HongWei, W.J.Sun, and Z.Chen, Network externalities, entry and choices of compatibility strategies of firms, Systems Engineering, 25(1) (2007) 66-71.

13. J.I.Hongwei, Network externalities, switching-cost and analysis of compatibility decisions of firms, Chinese Journal of Management, 4(6) (2007) 729-736.

14. W.J.Sun and H.M.Chen, Analysis of dynamical evolution of market structure based on network externality, Management Sciences in China, (2006). 